\title{
A prospective study of the clinical outcomes and prognosis associated with comorbid COPD in the atrial fibrillation population
}

This article was published in the following Dove Medical Press journal: International Journal of COPD

\section{Moisés Rodríguez- \\ Mañero, ${ }^{1-3, *}$ Estrella López- \\ Pardo, ${ }^{4, *}$ Alberto Cordero, ${ }^{3,5}$ \\ Alberto Ruano-Ravina, ${ }^{4}$ \\ José Novo-Platas, ${ }^{4}$ María \\ Pereira-Vázquez,' Álvaro \\ Martínez-Gómez,' Javier \\ García-Seara, ${ }^{1-3}$ Jose-Luis \\ Martínez-Sande, ${ }^{1-3}$ Carlos \\ Peña-Gil, ${ }^{1-3}$ Pilar Mazón, ${ }^{1-3}$ \\ Jose María García-Acuña, ${ }^{1-3}$ \\ Luis Valdés-Cuadrado, ${ }^{4,6}$ José \\ Ramón González-Juanatey ${ }^{1-3}$}

'Servicio de Cardiología, Hospital Universitario Santiago de Compostela, Santiago de Compostela, Spain; 2IDIS (Instituto para el Desarrollo e Integración de la Salud), Madrid, Spain; ${ }^{3}$ CIBERCV (Centro de Investigación Biomédica en Red de Enfermedades Cardiovasculares), Madrid, Spain; ${ }^{4}$ Xerencia de Xestión Integrada, Hospital Universitario Santiago de Compostela, Santiago de Compostela, Spain; ${ }^{5}$ Hospital Universitario San Juan de Alicante, Sant Joan d'Alacant, Spain; ${ }^{6}$ Servicio de Neumología, Hospital Universitario Santiago de Compostela, Santiago de Compostela, Spain

*These authors contributed equally to this work

Correspondence: Moisés

Rodríguez-Mañero

Hospital Clínico Universitario, Travesía

da Choupana SN, 15706 Santiago de

Compostela, Spain

Tel +34 6I 6903275

Fax +34981950000

Email moirmanero@gmail.com
Background: Patients with COPD are at higher risk of presenting with atrial fibrillation (AF). Information about clinical outcomes and optimal medical treatment of AF in the setting of COPD remains missing. We aimed to describe the prevalence of COPD in a sizeable cohort of real-world AF patients belonging to the same healthcare area and to examine the relationship between comorbid COPD and AF prognosis.

Methods: Prospective analysis performed in a specific healthcare area. Data were obtained from several sources within the "data warehouse of the Galician Healthcare Service" using multiple analytical tools. Statistical analyses were completed using SPSS 19 and STATA 14.0. Results: A total of 7,990 (2.08\%) patients with AF were registered throughout 2013 in our healthcare area $(n=348,985)$. Mean age was $76.83 \pm 10.51$ years and $937(11.7 \%)$ presented with COPD. COPD patients had a higher mean $\mathrm{CHA}_{2} \mathrm{DS}_{2}$-VASc $(4.21$ vs $3.46 ; P=0.02)$ and received less beta-blocker and more digoxin therapy than those without COPD. During a mean follow-up of $707 \pm 103$ days, 1,361 patients (17\%) died. All-cause mortality was close to two fold higher in the COPD group $(28.3 \%$ vs $15.5 \% ; P<0.001)$. Independent predictive factors for all-cause mortality were age, heart failure, diabetes, previous thromboembolic event, dementia, COPD, and oral anticoagulation (OA). There were nonsignificant differences in thromboembolic events $(1.7 \%$ vs $1.5 \% ; P=0.7)$, but the rate of hemorrhagic events was significantly higher in the COPD group $(3.3 \%$ vs $1.9 \% ; P=0.004)$. Age, valvular AF, OA, and COPD were independent predictive factors for hemorrhagic events. In COPD patients, age, heart failure, vasculopathy, lack of OA, and lack of beta-blocker use were independent predictive factors for all-cause mortality.

Conclusion: AF patients with COPD have a higher incidence of adverse events with significantly increased rates of all-cause mortality and hemorrhagic events than AF patients without COPD. However, comorbid COPD was not associated with differences in cardiovascular death or stroke rate. OA and beta-blocker treatment presented a risk reduction in mortality while digoxin use exerted a neutral effect.

Keywords: atrial fibrillation, big data, $\mathrm{CHA}_{2} \mathrm{DS}_{2}-\mathrm{VASc}, \mathrm{COPD}$, stroke

\section{Background}

COPD represents one of the most prevalent medical conditions. ${ }^{1-3}$ It is associated with significant morbidity as well as economic and social burden. ${ }^{1}$ Moreover, COPD is one of the leading causes of mortality worldwide and is expected to become the third leading cause of death by $2020 .{ }^{1}$ Another highly prevalent medical disorder is atrial fibrillation (AF). ${ }^{4} \mathrm{AF}$ patients have an amplified risk of serious complications including death, stroke, and congestive heart failure (CHF). ${ }^{4-7}$ 
These two conditions are often seen together in light of their high individual prevalence rates. Patients who have both conditions impose high resource consumption and incur worse quality of life overall. Numerous studies corroborate that COPD patients have an increased risk of developing cardiac arrhythmias ${ }^{8,9}$ with a four fold risk of AF. ${ }^{8}$ Among COPD patients, the simultaneous presence of AF confers a higher risk of hospitalization compared with COPD patients without AF ${ }^{10}$ Medical treatment is a major concern in this setting. Beta-blocker and digoxin use is a matter of controversy - the former in COPD patients and the latter in the overall population and specifically in AF. Subsequently, the lower frequency of beta-blocker use and higher frequency of digoxin use in the COPD population may have adverse long-term outcomes.

Notably, most of the studies analyzing the association between AF and COPD are retrospective in nature, and information relating to outcomes remains lacking.

This study aimed to 1) quantify the prevalence of COPD in a large cohort of real-world European AF patients belonging to the same healthcare area; and 2) to describe the association of comorbid COPD with prognosis in AF, specifically in relation to all-cause mortality.

\section{Methods}

\section{Study population}

The study population was acquired from the database information system of the Galician Healthcare Service. ${ }^{11}$ The information was acquired from several sources within the "data warehouse of the Galician Healthcare Service" using analytical tools (Complex Analysis Information Systems) (Sistemas de Información de Análisis Complejo, SIAC) to retrieve normalized and structured data about patient characteristics (SIAC-CID), primary health care (SIAC-AP), hospital discharges (SIAC-HA), and pharmaceutical information (SIAC-PF). Clinical coding is based on international classifications: International Classification of Primary Care-2-E, International Classification of Diseases, ninth revision, Clinical Modification (CIE-9-MC), and Anatomical, Therapeutic, Chemical classification system and is detailed in the Supplementary material. The study was approved by the Ethics Committee of Clinical Research (comité ético de investigación clínica de galicia).

\section{$\mathrm{AF}$ and COPD}

A qualified expert searched for specific data from different modules of the health information system and matched them with an active episode of AF for each patient using a personal identification code. Finally, once patients were identified, a data manager confirmed the correct codification of the patients (Supplementary material).

All patients coded with COPD were successively verified by one investigator (ELP). COPD was defined by a $\mathrm{FEV}_{1} / \mathrm{FVC}$ ratio $<0.70$ after $400 \mu \mathrm{g}$ of inhaled albuterol. ${ }^{12}$ In line with previous studies, patients with a previous history of asthma, bronchiectasis, tuberculosis, or other confounding diseases such as severe CHF (New York Heart Association stage III-IV), obliterative bronchiolitis, or diffuse panbronchiolitis were excluded. Patients with COPD were clinically stable receiving standard medical therapy according to the American Thoracic Society/European Respiratory Society guidelines. ${ }^{13}$

\section{Complications (SIAC HA-CMBD)}

The Minimum Basic Data Set (MBDS) is a set of variables obtained at the time of hospital discharge, which contains administrative, clinical, and demographic data and provides information on the patient, his/her environment, the healthcare-providing institution, and the hospital course. The clinical variables (primary diagnosis, other diagnosis, surgical procedure, and other therapeutic diagnostic procedures) are the most useful instruments for the calculation of clinical activity and are coded according to the CIE-9-MC. Their use is required in all public Spanish hospitals.

The lack of efficacy and the presence of adverse effects were analyzed from the MBDS by identifying the primary and secondary diagnoses related to thromboembolic events (ischemic ictus, deep venous thrombosis, and pulmonary embolism) and hemorrhagic processes (gastrointestinal, retroperitoneal, hematuria, nervous system, and unspecified) via their CIE-9-MC (eighth and ninth revisions) codes.

The causes of death were divided into inpatient and outpatient deaths. Also based on the codes assigned to the primary cause of death, deaths were classified by a single investigator (MRM) as 1) cardiovascular death (myocardial infarction, heart failure, arrhythmia, endocarditis, embolism, or hemorrhage) and 2) non-cardiovascular death (infectious, oncologic, traumatic, digestive, renal failure, respiratory failure, hematologic, rhabdomyolysis, diabetes mellitus, neurologic disorders, vascular failure, and gynecologic).

\section{Statistical analysis}

In an initial descriptive analysis, Gaussian continuous variables were expressed as mean and standard deviation and non-Gaussian continuous variables were expressed as median (minimum and maximum). To identify the differences between study groups, the parametric ANOVA test 
was utilized for Gaussian variables and the Kruskal-Wallis test was used for non-Gaussian variables. Categorical variables were compared using the chi-squared test. All-cause mortality was calculated using Cox regression model. The qualitative and quantitative variables included in the models were the following: quantitative: age and $\mathrm{CHA}_{2} \mathrm{DS}_{2}-\mathrm{VASc}$ score; qualitative: gender, valvular and non-valvular AF, peripheral arteriopathy, diabetes mellitus (insulin-dependent or non-insulin dependent), arterial hypertension, pulmonary thromboembolism, ischemic transitory accident/ stroke, heart failure, acute myocardial infarction, COPD, death (inpatient and outpatient) or treatment with warfarin/ acenocumarol, aspirin, clopidogrel, rivaroxaban, apixaban or dabigatran, beta-blockers, angiotensin-converting enzyme inhibitors/angiotensin II receptor antagonist (ACEI/ARAII), and digoxin.

The statistically significant $P$-values were obtained through a two-sided test; $P$-values $<0.05$ were considered statistically significant. All statistic calculations were completed using the SPSS 19 and STATA 14.0 programs.

\section{Results}

Overall there were 7,990 (2.08\%) subjects with AF (846; $10.6 \%$ valvular $\mathrm{AF}$ and the rest 7,144; $89.4 \%$ non-valvular AF) in the healthcare area of Santiago de Compostela (383,000 subjects) on January 1, 2013. Out of 53,684 subjects aged between 0 and 14 years, there were 0 cases with AF; in the 14-64 years age group, there were 956 cases of AF
$(0.38 \%)$; and finally, from 91,052 individuals $(7.72 \%)$ of age $>64$ years, there were 7,034 AF cases.

\section{Baseline characteristics}

The mean age of the study population was $76.83 \pm 10.51$ years; 4,056 patients (50.8) were women, and 937 (11.7\%) patients had a comorbid COPD diagnosis (Table 1). Mean CHA $\mathrm{DS}_{2}-$ VASc score was 3.5 \pm 1.54 . As shown in Table 2, patients with COPD were more frequently men than women. They were also older and had higher rates of diabetes, vasculopathy and heart failure than their counterparts without COPD. About $75.5 \%$ of patients with COPD received oral anticoagulation (OA) vs $72.2 \%$ of patients without it $(P=0.03)$. There was no difference with regard to antiplatelet therapy $(12.4 \%$ vs $13.2 \%$, respectively; $P=0.48$ ). There were clear differences in beta-blocker treatment rate $(45.3 \%$ vs $28.2 \% ; P<0.001)$ and digoxin prescription $(32.1 \%$ vs $41.0 \% ; P<0.001)$ for those without COPD and those with the diagnosis, respectively.

Patients with COPD had a higher mean $\mathrm{CHA}_{2} \mathrm{DS}_{2}-\mathrm{VASc}$ score (4.21 vs 3.46, $P=0.02$ ), and thus, this population had a higher proportion of patients with high thromboembolic risk $\left(\mathrm{CHA}_{2} \mathrm{DS}_{2}-\mathrm{VASc} \geq 2 ; 95.3 \%\right.$ vs $\left.89.2 \% ; P<0.001\right)$ compared to those without COPD.

\section{Events}

\section{Mortality}

During a mean follow-up of $707 \pm 103$ days, 1,361 patients (17\%) died (all-cause mortality), 478 of them in the hospital

Table I Differences in the distribution of the $\mathrm{CHA}_{2} \mathrm{DS}_{2}$-VASc components according to gender

\begin{tabular}{|c|c|c|c|c|}
\hline & Male $(n=3,934 ; 49.2 \%)$ & Female $(n=4,056 ; 50.8 \%)$ & Total $(n=7,990)$ & $P$-value \\
\hline Age (SD)* & $74.42(11.18)$ & $79.17(9.23)$ & $76.83(10.5 I)$ & $<0.001$ \\
\hline Age $<65$ years $*$ & $681(17.3 \%)$ & $275(6.7 \%)$ & $956(12.0 \%)$ & $<0.001$ \\
\hline Heart failure* & I,I5I (29.3\%) & $\mathrm{I}, 025$ (25.3\%) & $2,176(27.2 \%)$ & $<0.001$ \\
\hline Hypertension* & $2,572(65.4 \%)$ & $3,020(74.5 \%)$ & $5,592(70.0 \%)$ & $<0.001$ \\
\hline Diabetes mellitus* & $975(24.8 \%)$ & $906(22.3 \%)$ & $\mathrm{I}, 88 \mathrm{I}(23.5 \%)$ & 0.010 \\
\hline Vasculopathy* & $301(7.7 \%)$ & $209(5.2 \%)$ & $510(6.4 \%)$ & $<0.001$ \\
\hline Previous thromboembolic event & $353(9 \%)$ & $38 \mathrm{I}(9.4 \%)$ & $734(9.2 \%)$ & 0.515 \\
\hline Valvular AF & $379(9.6 \%)$ & 467 (II.7\%) & $846(10.6 \%)$ & 0.006 \\
\hline Dementia* & $76(1.9 \%)$ & $211(5.2 \%)$ & $287(3.6 \%)$ & $<0.001$ \\
\hline COPD & $636(16.2 \%)$ & $30 \mathrm{I}(7.4 \%)$ & 937 (11.7\%) & $<0.001$ \\
\hline Antiplatelets & $515(13.1 \%)$ & $532(13.1 \%)$ & I,047 (I3.1\%) & 0.973 \\
\hline Oral anticoagulants & 2,825 (71.8\%) & 2,974 (73.3\%) & $5,799(72.6 \%)$ & 0.129 \\
\hline $\mathrm{CHA}_{2} \mathrm{DVAS}_{2}-\mathrm{Vasc}<2$ & $682(17.3 \%)$ & $127(3.1 \%)$ & $809(10.1 \%)$ & $<0.001$ \\
\hline Beta-blockers & I,72I (43.7\%) & I,735 (42.8\%) & $3,456(43.3 \%)$ & 0.381 \\
\hline ACEI/ARAII & 2,342 (59.5\%) & $2,526(62.3 \%)$ & $4,868(60.9 \%)$ & 0.012 \\
\hline Digoxin & $\mathrm{I}, \mathrm{I} 20$ (28.5\%) & I,53। (37.7\%) & $2,65 \mathrm{I}(33.2 \%)$ & $<0.001$ \\
\hline
\end{tabular}

Note: *Statistically significant.

Abbreviations: ACEl, angiotensin-converting enzyme inhibitors; AF, atrial fibrillation; ARAll, angiotensin II receptor antagonists; SD, standard deviation. 
Table 2 Differences in the baseline profile and in the rate of events in patients with and without COPD

\begin{tabular}{|c|c|c|c|c|}
\hline & No COPD $(n=7,053 ; 88.3 \%)$ & COPD (n=937; II.7\%) & Total $(n=7,990)$ & $P$-value \\
\hline \multicolumn{5}{|l|}{ Baseline characteristics } \\
\hline Age (SD) & $76.5(10.57)$ & $82.01(7.89)$ & $76.83(10.5 \mathrm{I})$ & $<0.001$ \\
\hline Female & $3,755(53.2 \%)$ & $301(32.1 \%)$ & $4,056(50.8 \%)$ & $<0.001$ \\
\hline Heart failure & I,787 (25.3\%) & $389(41.5 \%)$ & $2,176(27.2 \%)$ & $<0.001$ \\
\hline Hypertension & $4,926(69.8 \%)$ & $666(71.1 \%)$ & $5,592(70.0 \%)$ & 0.43 \\
\hline Diabetes mellitus & $1,630(23.1 \%)$ & $25 I(26.8 \%)$ & I,88I (23.5\%) & 0.013 \\
\hline Vasculopathy & $430(6.1 \%)$ & $80(8.5 \%)$ & $510(6.4 \%)$ & 0.004 \\
\hline Previous thromboembolic event & $647(9.2 \%)$ & 87 (9.3\%) & $734(9.2 \%)$ & 0.91 \\
\hline Valvular AF & $742(10.5 \%)$ & $104(11.1 \%)$ & $846(10.6 \%)$ & 0.58 \\
\hline $\mathrm{CHA}_{2} \mathrm{DVAS}_{2}-\mathrm{Vasc}<2$ & $765(10.8 \%)$ & 44 (4.7\%) & 809 (10.1\%) & $<0.001$ \\
\hline Antiplatelets & 931 (13.2\%) & $116(12.4 \%)$ & I,047 (13.1\%) & 0.485 \\
\hline Oral anticoagulants & $5,092(72.2 \%)$ & 797 (75.5\%) & $5,799(72.6 \%)$ & 0.036 \\
\hline Beta-blockers & $3,192(45.3 \%)$ & $264(28.2 \%)$ & $3,456(43.3 \%)$ & $<0.001$ \\
\hline ACEI/ARAII & $4,300(61.0 \%)$ & $568(60.6 \%)$ & 4,868 (60.9\%) & 0.837 \\
\hline Digoxin & 2,267 (32.1\%) & $384(41.0 \%)$ & $2,65 I$ (33.2\%) & $<0.001$ \\
\hline \multicolumn{5}{|l|}{ Outcomes } \\
\hline Intracranial hemorrhage & $25(0.4 \%)$ & $5(0.5 \%)$ & $30(0.4 \%)$ & 0.400 \\
\hline Hemorrhagic events & $133(1.9 \%)$ & 31 (3.3\%) & $164(2.1 \%)$ & 0.004 \\
\hline Stroke & $109(1.5 \%)$ & $16(1.7 \%)$ & $125(1.6 \%)$ & 0.707 \\
\hline In-hospital dead & $368(5.2 \%)$ & $110(11.7 \%)$ & $478(6.0 \%)$ & 0.000 \\
\hline All-cause mortality & $1,096(15.5 \%)$ & $265(28.3 \%)$ & I,36I (I7.0\%) & 0.000 \\
\hline
\end{tabular}

Abbreviations: ACEI, angiotensin-converting enzyme inhibitors; AF, atrial fibrillation; ARAll, angiotensin II receptor antagonists; SD, standard deviation.

( $6 \%$ of total). For inpatient deaths, a diagnostic code is always assigned by primary cause of admission. This allowed us to discern the cause of death of these patients, which was cardiovascular for 175 subjects (36.6\%) and non-cardiovascular for the remaining. Thirty-eight participants $(7.9 \%)$ had a hemorrhagic event, with $30(0.4 \%)$ of them having cerebral hemorrhage. Of these 30 patients, 25 were on OA, three were on antiplatelet therapy, and two were not receiving either of the former. All these events happened in patients with $\mathrm{CHA}_{2} \mathrm{DS}_{2}$-VASc scores $\geq 2$.

Differences in overall mortality were observed between patients with and without COPD (Figure 1; Table 2). In the multivariable analysis, age, heart failure, diabetes, previous thromboembolic event, vasculopathy, COPD, valvular AF, OA antiplatelet, and absence of beta-blocker therapy were independent predictive factors for all-cause mortality (Table 3). COPD had the highest HR for all-cause mortality which was higher than those of independent $\mathrm{CHA}_{2} \mathrm{DS}_{2}$-VASc components (HR $=1.92,95 \%$ CI: $1.54-2.40 ; P<0.001)$.

When the analysis was performed in the subgroup of patients with COPD, age, heart failure, vasculopathy, lack of $\mathrm{OA}$, and lack of beta-blocker use were independent predictive factors for all-cause mortality (Table 4).

\section{Thromboembolic and hemorrhagic events}

There were 125 ictus cases (1.6\%) during the follow-up. There was a non-significant difference between the incidenceinCOPDandnon-COPDpatients(1.7\%vs $1.5 \% ; P=0.7)$. Independent factors related to ictus were age $(\mathrm{HR}=1.04$;

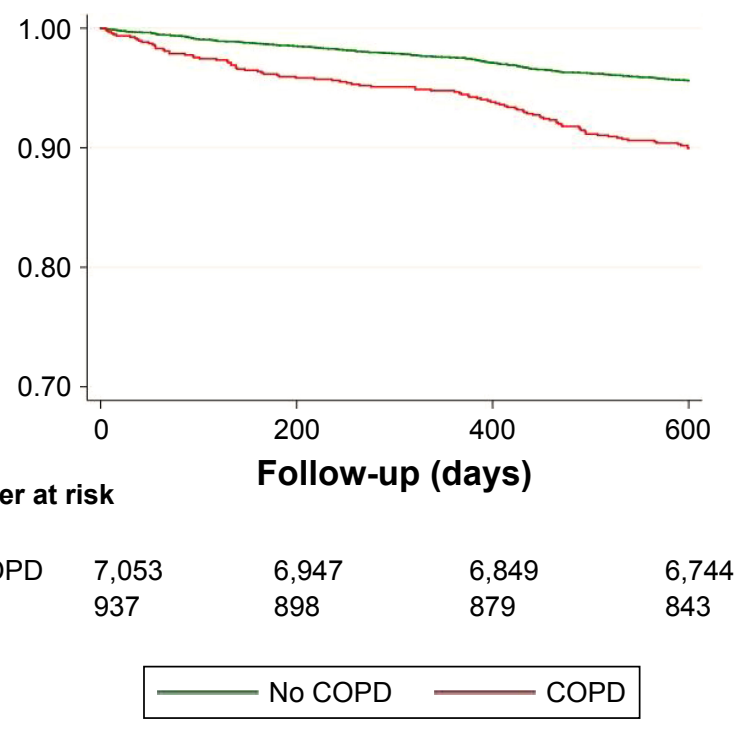

Figure I Kaplan-Meier curves for all-cause death at I-year follow-up with respect to the presence of COPD. 
Table 3 Univariable and multivariable Cox regression analyses for overall mortality in the whole population

\begin{tabular}{|c|c|c|c|c|c|c|}
\hline \multicolumn{7}{|l|}{ All-cause mortality } \\
\hline & HR & $95 \% \mathrm{Cl}$ & $P$-value & HR & $95 \% \mathrm{Cl}$ & $P$-value \\
\hline & \multicolumn{3}{|c|}{ Univariable } & \multicolumn{3}{|c|}{ Multivariable } \\
\hline Age (years)* & 1.11 & $1.10-1.12$ & $<0.001$ & 1.08 & $1.07-1.09$ & $<0.001$ \\
\hline Female & 1.21 & $1.07-1.36$ & 0.002 & 1.11 & $0.92-1.34$ & 0.227 \\
\hline Heart failure* & 2.00 & $1.77-2.26$ & $<0.001$ & 1.93 & $1.60-2.34$ & $<0.001$ \\
\hline Arterial hypertension & 1.18 & $1.03-1.34$ & 0.013 & 1.16 & $0.93-1.45$ & 0.198 \\
\hline Thromboembolic event* & 1.73 & $1.44-2.06$ & $<0.001$ & 1.43 & I.10-1.86 & 0.008 \\
\hline Vasculopathy* & 1.39 & $1.11-1.73$ & 0.003 & 1.51 & $1.13-2.02$ & 0.006 \\
\hline Diabetes mellitus* & 1.35 & $1.18-1.54$ & $<0.001$ & 1.33 & $1.09-1.62$ & 0.005 \\
\hline Valvular $\mathrm{AF}^{*}$ & 4.69 & $3.69-5.96$ & $<0.001$ & 1.40 & I.09-I.82 & 0.009 \\
\hline Dementia & 4.69 & $3.69-5.96$ & $<0.001$ & 1.27 & $0.86-1.87$ & 0.234 \\
\hline COPD* & 1.93 & $1.68-2.20$ & 0.000 & 1.92 & I.54-2.40 & $<0.00 \mathrm{I}$ \\
\hline Oral anticoagulation* & 0.75 & $0.66-0.86$ & $<0.001$ & 0.80 & $0.70-0.92$ & 0.002 \\
\hline Antiplatelet* & 1.21 & $1.03-1.43$ & 0.024 & 1.60 & $1.20-2.12$ & 0.001 \\
\hline Beta-blockers* & 0.62 & $0.43-0.90$ & 0.012 & 0.50 & $0.4 I-0.62$ & $<0.001$ \\
\hline ACEI/ARAII & 0.79 & $0.7 \mathrm{I}-0.88$ & $<0.001$ & 0.95 & $0.78-1.16$ & 0.642 \\
\hline Digoxin & 1.18 & $1.06-1.32$ & 0.003 & 0.96 & $0.79-1.17$ & 0.699 \\
\hline
\end{tabular}

Note: *Significant in the multivariable analysis.

Abbreviations: ACEl, angiotensin-converting enzyme inhibitors; AF, atrial fibrillation; ARAll, angiotensin II receptor antagonists.

95\% CI: $1.02-1.06 ; P<0.001)$, female gender $(\mathrm{HR}=1.50 ; 95 \%$ CI: 1.03-2.18; $P=0.03$ ) and previous thromboembolic event(s) (HR $=1.96 ; 95 \%$ CI: $1.24-3.05 ; P=0.004)$. OA was a protective factor for cerebral thromboembolic events $(\mathrm{HR}=0.65$; 95\% CI: $0.42-0.99 ; P=0.04)$. COPD was not associated with the development of thromboembolic events (Table 5).
There were 164 hemorrhagic events $(2.1 \%)(1.9 \%$ in patients without COPD and $3.3 \%$ in patients with COPD, $P=0.004)$. For the multivariable model the following factors increased the risk of a hemorrhagic event: age (HR $=1.03 ; 95 \% \mathrm{CI}: 1.01-1.05 ; P<0.001$ ), valvular $\mathrm{AF}$ (HR $=1.99 ; 95 \%$ CI: 1.35-2.95; $P<0.001)$, OA $(\mathrm{HR}=1.45$;

Table 4 Univariable and multivariable Cox regression analyses for overall mortality in the COPD population

\begin{tabular}{|c|c|c|c|c|c|c|}
\hline \multicolumn{7}{|l|}{ All-cause mortality } \\
\hline & HR & $95 \% \mathrm{CI}$ & $P$-value & HR & $95 \% \mathrm{Cl}$ & $P$-value \\
\hline & \multicolumn{3}{|c|}{ Univariable } & \multicolumn{3}{|c|}{ Multivariable } \\
\hline Age (years)* & 1.04 & $1.02-1.07$ & $<0.001$ & 1.03 & $1.01-1.06$ & 0.006 \\
\hline Female & 0.93 & $0.63-1.38$ & 0.71 & & & \\
\hline Heart failure* & 2.00 & $1.77-2.26$ & $<0.001$ & 1.76 & $1.20-2.57$ & 0.003 \\
\hline Arterial hypertension & 1.43 & $0.91-2.23$ & 0.117 & & & \\
\hline Thromboembolic event & 1.21 & $0.66-2.21$ & 0.530 & & & \\
\hline Vasculopathy* & 1.96 & $1.15-3.32$ & 0.013 & 1.86 & $1.10-3.17$ & 0.021 \\
\hline Diabetes mellitus & 1.38 & $0.93-2.05$ & 0.116 & & & \\
\hline Valvular AF & 1.51 & $0.91-2.54$ & 0.116 & & & \\
\hline Dementia & 1.64 & $0.77-3.53$ & 0.205 & & & \\
\hline Oral anticoagulation* & 0.64 & $0.43-0.96$ & 0.030 & 0.64 & $0.5 I-0.79$ & 0.046 \\
\hline Antiplatelet & 1.87 & $1.17-2.99$ & 0.009 & 1.59 & $0.88-2.85$ & 0.122 \\
\hline Beta-blockers* & 0.58 & $0.36-0.94$ & 0.026 & 0.62 & $0.38-0.99$ & 0.048 \\
\hline ACEI/ARAII & 0.84 & $0.57-1.22$ & 0.352 & & & \\
\hline Digoxin & 1.15 & $0.79-1.67$ & 0.479 & & & \\
\hline
\end{tabular}

Note: *Significant in the multivariable analysis.

Abbreviations: ACEI, angiotensin-converting enzyme inhibitors; AF, atrial fibrillation; ARAll, angiotensin II receptor antagonists. 
Table 5 Univariable and multivariable Cox regression analyses for thromboembolic events and hemorrhagic events in the whole population

\begin{tabular}{|c|c|c|c|c|c|c|}
\hline & HR & $95 \% \mathrm{Cl}$ & $P$-value & HR & $95 \% \mathrm{Cl}$ & $P$-value \\
\hline & \multicolumn{6}{|c|}{ Thromboembolic events } \\
\hline & \multicolumn{3}{|c|}{ Univariable } & \multicolumn{3}{|c|}{ Multivariable } \\
\hline \multicolumn{7}{|c|}{ Thromboembolic events } \\
\hline Age (years)* & 1.05 & $1.03-1.07$ & $<0.001$ & 1.04 & $1.02-1.06$ & $<0.001$ \\
\hline Female* & 1.79 & $1.24-2.58$ & 0.002 & 1.50 & $1.03-2.18$ & 0.03 \\
\hline Heart failure & 0.88 & $0.60-1.30$ & 0.53 & & & \\
\hline Arterial hypertension & 0.89 & $0.6 \mathrm{I}-1.29$ & 0.54 & & & \\
\hline Vasculopathy & 1.19 & $0.60-2.34$ & 0.61 & & & \\
\hline Previous TE* & 1.51 & $1.20-1.90$ & $<0.001$ & 1.96 & I.24.3.05 & 0.004 \\
\hline Diabetes mellitus & 0.92 & $0.60-1.40$ & 0.68 & & & \\
\hline Valvular AF & 1.36 & $0.8 \mathrm{I}-2.27$ & 0.23 & & & \\
\hline Dementia & 1.15 & $0.47-2.83$ & 0.75 & & & \\
\hline Oral anticoagulation* & 0.53 & $0.37-0.75$ & $<0.001$ & 0.65 & $0.42-0.99$ & 0.004 \\
\hline Antiplatelet & 2.24 & 1.49-3.37 & $<0.001$ & 1.58 & $0.96-2.60$ & 0.07 \\
\hline Beta-blockers & 0.62 & $0.42-0.90$ & 0.012 & 0.79 & $0.54-1.17$ & 0.24 \\
\hline ACEI/ARAII & 0.99 & $0.69-1.43$ & 0.98 & & & \\
\hline Digoxin & 0.86 & $0.7 I-I .06$ & 0.16 & & & \\
\hline \multicolumn{7}{|l|}{ Hemorrhagic events } \\
\hline Age (years)* & 1.03 & $1.02-1.05$ & $<0.001$ & 1.03 & $1.01-1.05$ & $<0.001$ \\
\hline Female & 0.88 & $0.65-1.19$ & 0.4 & & & \\
\hline Heart failure & 0.70 & $0.5 \mathrm{I}-0.98$ & 0.036 & 0.91 & $0.65-1.27$ & 0.59 \\
\hline Arterial hypertension & 1.26 & $0.89-1.79$ & 0.19 & & & \\
\hline Vasculopathy & 0.99 & $0.53-1.89$ & 0.99 & & & \\
\hline Previous TE & 1.22 & $0.97-1.54$ & 0.084 & 1.16 & 0.92 .1 .46 & 0.198 \\
\hline Diabetes mellitus & 1.37 & $0.95-1.87$ & 0.09 & 1.28 & $0.91-1.80$ & 0.16 \\
\hline Valvular AF* & 2.10 & $1.43-3.09$ & $<0.001$ & 1.99 & $1.35-2.95$ & 0.001 \\
\hline Dementia & 0.52 & $1.65-1.62$ & 0.258 & & & \\
\hline COPD* & 1.86 & $1.26-2.75$ & 0.002 & 1.72 & $1.16-2.54$ & 0.007 \\
\hline Oral anticoagulation* & 1.55 & $1.05-2.28$ & 0.026 & 1.45 & $1.01-2.14$ & 0.04 \\
\hline Antiplatelet & 1.28 & $0.84-1.95$ & 0.24 & & & \\
\hline Beta-blockers & 0.89 & $0.65-1.22$ & 0.49 & & & \\
\hline ACEI/ARAII & 0.76 & $0.97-1.86$ & 0.076 & 1.26 & $0.90-1.75$ & 1.26 \\
\hline Digoxin & 1.40 & $1.02-1.91$ & 0.034 & 0.95 & $0.8 \mathrm{I}-1.12$ & 0.56 \\
\hline
\end{tabular}

Note: *Significant in the multivariable analysis.

Abbreviations: ACEl, angiotensin-converting enzyme inhibitors; AF, atrial fibrillation; ARAll, angiotensin II receptor antagonists; TE, thromboembolic event.

95\% CI: $1.01-2.14, P=0.04)$, and COPD (HR $=1.72 ; 95 \% \mathrm{CI}$ : 1.16-2.54; $P=0.007$ ) (Table 5).

\section{Discussion}

In the present study, we describe the outcomes of real-world AF patients and compare the results with the subgroup who had comorbid COPD. To the best of our knowledge, this is the largest sample size of patients with both conditions reported to date. A concomitant diagnosis of COPD was found in $11.7 \%$ of included AF patients. These patients are older and more likely to be male. While the factors with the highest influence on mortality in AF are concomitant heart failure and COPD (with close to twofold risk of mortality), in the subgroup of AF patients with COPD, the most important risk factors for death during follow-up were vasculopathy and heart failure. Interestingly, in these patients, OA and betablocker treatment presented an important risk reduction in mortality. COPD was independently associated with all-cause death and hemorrhagic events but not with cardiovascular death or thromboembolic episodes in AF patients. 
Importantly this analysis is not delimited by age or by any other parameter, since it includes the total population of patients with AF within our healthcare area. Therefore, these results are representative and have strong external validity with no selection bias. Moreover, the most significant endpoints including all-cause mortality and hemorrhagic/ thromboembolic events have been thoroughly collected.

\section{Background}

An expanding body of evidence reveals that COPD is associated with $\mathrm{AF} .{ }^{8,9,14}$ The Malmo Preventive Project reported that after adjustment for clinical variables, $\mathrm{FEV}_{1}$ was inversely associated with the incidence of $\mathrm{AF} .{ }^{15}$ The prevalence of COPD in AF patients in our healthcare area (almost 12\%) is similar to that study. ${ }^{15}$ However, in an American setting, the rate has been reported as high as $23 \% .{ }^{16}$ More recently, in the EURObservational Research Programme Pilot Survey on Atrial Fibrillation (EORP-AF) survey, COPD was found in $11 \%$ of AF patients. ${ }^{17}$

Several mechanisms of this association have been proposed.$^{18}$ First, the increasing age of the population could be one of the major determinants. ${ }^{3}$ Similarly, CHF and COPD often coexist, ${ }^{19,20}$ and both have the potential to impact one another. Our study shows that this association remains (CHF is present in $45 \%$ of those with COPD vs $25.3 \%$ of those without), emphasizing the conception that both the disorders are narrowly related. In addition to CHF, diabetes mellitus was more commonly present in COPD patients $(26.8 \%$ vs $23.1 \% ; P=0.013$ ). Hypoxia and hypercapnia have been involved in AF occurrence in COPD ${ }^{21}$ Previous studies have shown that the greater vulnerability of the atrium for reentrant arrhythmias by hypoxia is based on the combination of a moderate shortening of the wavelength and an increase in homogeneity in the conduction of premature wavefronts. ${ }^{18,22}$ Other groups have shown that MMP-9 expression and upregulation of HIF-1a/VEGF increase in fibrillating atria, which may contribute to the atrial structural remodeling seen in these patients. ${ }^{23-25}$ On the other hand, hypercapnia produces a marked and uniform increase in atrial refractoriness and a significant slowing in atrial conduction. ${ }^{22}$ Moreover, hypoxemia results in pulmonary arteriolar constriction leading to pulmonary arterial and right ventricular hypertension which may predispose to arrhythmias due to the resulting right atrial dilatation. ${ }^{26,27} \mathrm{COPD}$ also contributes to ventricular diastolic dysfunction, ${ }^{19,20,26,27}$ a conceivable pathophysiologic mechanism of AF initiation and/or perpetuation. ${ }^{26}$ Oxidative stress and inflammation represent major pathogenic mechanisms in $\mathrm{COPD},{ }^{28}$ but have also been associated with $\mathrm{AF}$ initiation and perpetuation. ${ }^{29}$ Finally, respiratory drugs have been shown to precipitate AF. Short- and long-acting beta-agonists, anticholinergic drugs, and methylxanthine agents may increase the risk of $\mathrm{AF}$ in $\mathrm{COPD} .^{18}$

\section{Clinical relevance}

In the EORP-AF Pilot registry, ${ }^{17}$ which had a smaller number of patients $(n=339)$ and shorter follow-up, COPD was linked with superior rates of cardiovascular death, all-cause mortality, and the compound outcome of thromboembolic event/bleeding/cardiovascular death. Similarly, Huang et $\mathrm{al}^{30}$ reported in 227 patients that the presence of COPD in patients with $\mathrm{AF}$ was an independent risk factor for 1-year all-cause and cardiovascular mortality but not a risk factor for stroke. In our population, COPD was indeed associated with all-cause mortality but not with cardiovascular death or thromboembolic events. Due to the longer follow-up of our cohort plus the higher number of patients, we believe that this association should be confirmed. Possibly, differences in the rate of beta-blocker use could have explained the differences existing in cardiovascular mortality. Beta-blockers have been conventionally contraindicated in COPD; however, current data imply that cardioselective beta-blockers are safe and lessen COPD exacerbations and mortality. ${ }^{31,32}$ In our population, beta-blockers exhibited a protective effect in all-cause mortality both in the general population and in COPD patients.

Another significant finding in our study is that digoxin was not associated with an increased risk for all-cause mortality. This series represents one of the largest contemporary series of COPD patients, and after adjustment for clinical factors, digoxin use had a neutral association with outcomes. Nevertheless, based on the multiple conflicting observational studies about digoxin's safety and its potential concerns, along with the well-known protective effects of beta-blockers, it seems logical to reserve this drug for those patients intolerant to beta-blockers or for those situations where dual therapy is still needed in order to achieve an adequate rate control.

It is important to highlight that $75 \%$ of our COPD patients were maintained on OA (significantly higher than patients without COPD). This could have explained the lack of difference with regard to stroke rates and the significant increase in the rate of hemorrhagic events, in particular with regard to gastrointestinal bleeding. Nevertheless, COPD was independently associated with all-cause mortality in the multivariable analysis, pointing toward an independent mechanism underlying this association. In a recent study, the rate of recurrence of peptic ulcer bleeding (PUB) was significantly higher in COPD patients than in the non-COPD-matched 
controls, which goes in line with our observation. The association between hemorrhagic events and COPD might be secondary to numerous factors: ${ }^{33} \mathrm{COPD}$ represents a systemic inflammation. Oxidative stress may cause cytotoxic injury of the mucosa by creating reactive oxygen species. ${ }^{34}$ Moreover, cigarette smoke exposure in patients with COPD may delay ulcer healing. ${ }^{35}$ Finally, steroid use in COPD patients has been related to delayed ulcer healing. ${ }^{36}$ These presumed mechanisms may prompt patients with COPD to develop recurrent PUB and could explain - at least partially - the higher event rate found in this subset of patients. Due to the relevance of this novel finding, further studies addressing this relationship should be performed.

Our "real-world" data reinforce the existing evidence regarding the amplified risks in comorbid AF and COPD. Intensified clinical follow-up should be performed in this subgroup of patients. A comprehensive clarification of the pathophysiological mechanisms linking COPD to AF could lead to better therapeutic options and reduction in mortality in this subset of patients.

\section{Limitations}

There are some limitations of our study that should be acknowledged. First, it is important to highlight the fact that registered codes are from multiple physicians and are not reviewed by an independent observer, which could lead to some coding errors (ie, wrong coding of a disease for a patient). However, given the fact that it is a disease frequently encountered in several specialties, we believe that the proportion of erroneously coded patients is low, and therefore, it should not have modified the conclusions of this study. The protective effect of beta-blockers in the COPD population could be the result of beta-blocker prescription in patients with less severe COPD. The cox regression model was not adjusted for COPD severity, subsequently it is plausible that minor/early stages of the disease are not as strongly associated with the outcomes of interest as compared to those patients with more severe manifestations of the disease, where the weight of the association could be higher. Cigarette smoke exposure was not available in our records and hence was not considered in the analysis. This could also have had relevance in terms of outcomes. Finally, the cause of death is based on a diagnostic code assigned by the primary cause of admission, which could have been in some cases dissimilar to the final cause of death.

\section{Conclusion}

AF patients with COPD have a greater incidence of adverse events with significantly increased rates of all-cause mortality and hemorrhagic events than AF patients without COPD. However, comorbid COPD was not associated with differences in cardiovascular death or stroke rate. OA and betablocker treatment presented a risk reduction in mortality while digoxin use exerted a neutral effect.

\section{Disclosure}

The authors report no conflicts of interest in this work.

\section{References}

1. Fabbri LM, Hurd SS, GOLD Scientific Committee. Global strategy for the diagnosis, management and prevention of COPD: 2003 update. Eur Respir J. 2003;22(1):1-2.

2. Rycroft CE, Heyes A, Lanza L, Becker K. Epidemiology of chronic obstructive pulmonary disease: a literature review. Int J Chron Obstruct Pulmon Dis. 2012;7:457-494.

3. Vogelmeier CF, Criner GJ, Martínez FJ, et al. Global strategy for the diagnosis, management, and prevention of chronic obstructive lung disease 2017 report: gold executive summary. Arch Bronconeumol. 2017; 53(3):128-149.

4. Benjamin EJ, Wolf PA, D’Agostino RB, Silbershatz H, Kannel WB, Levy D. Impact of atrial fibrillation on the risk of death: the Framingham Heart study. Circulation. 1998;98(10):946-952.

5. Conen D, Chae CU, Glynn RJ, et al. Risk of death and cardiovascular events in initially healthy women with new-onset atrial fibrillation. JAMA . 2011;305(20):2080-2087.

6. Wang TJ, Larson MG, Levy D, et al. Temporal relations of atrial fibrillation and congestive heart failure and their joint influence on mortality: the Framingham Heart study. Circulation. 2003;107(23):2920-2925.

7. Wolf PA, Abbott RD, Kannel WB. Atrial fibrillation as an independent risk factor for stroke: the Framingham study. Stroke. 1991;22(8): 983-988.

8. Chen W, Thomas J, Sadatsafavi M, Fitzgerald JM. Risk of cardiovascular comorbidity in patients with chronic obstructive pulmonary disease: a systematic review and meta-analysis. Lancet Respir Med. 2015; 3(8):631-639.

9. Konecny T, Park JY, Somers KR, et al. Relation of chronic obstructive pulmonary disease to atrial and ventricular arrhythmias. Am J Cardiol. 2014;114(2):272-277.

10. Sidney S, Sorel M, Quesenberry CP, Deluise C, Lanes S, Eisner MD. COPD and incident cardiovascular disease hospitalizations and mortality: Kaiser Permanente medical Care program. Chest. 2005;128(4): 2068-2075.

11. Sistema de información poblacional del Servicio Gallego de Salud [Population information system of the Galician Service of Health]. Available from: https://www.sergas.es/bucen/listado-areas-influenci a? idTipoTit $=1 \&$ descTipoTit $=$ P $\% 25 \mathrm{c} 3 \% 25$ bablica $\&$ pro $=15 \&$ dpro $=\mathrm{A}$ $\% 2 \mathrm{bCORU} \% 25 \mathrm{c} 3 \% 2591 \mathrm{~A} \&$ busTR $=$ CENTRO $\% 2 \mathrm{bGENERAL} \% 252$ $\mathrm{c} \& \operatorname{codHosp}=150200 \&$ nomHosp=COMPLEXO+HOSPITALARIO+ UNIVERSITARIO+DE+SANTIAGO. Accessed January 16, 2019.

12. Celli BR, MacNee W, Agusti A, ATS/ERS Task Force. Standards for the diagnosis and treatment of patients with COPD: a summary of the ATS/ERS position paper. Eur Respir J. 2004;23(6):932-946.

13. Celli BR, Decramer M, Wedzicha JA, et al. An official American thoracic Society/European Respiratory Society statement: research questions in COPD. Eur Respir J. 2015;45(4):879-905.

14. Johnson LS, Juhlin T, Engström G, Nilsson PM. Reduced forced expiratory volume is associated with increased incidence of atrial fibrillation: the Malmo preventive project. Europace. 2014;16(2):182-188.

15. European Heart Rhythm Association, European Association for Cardio-Thoracic Surgery, Camm AJ, et al. Guidelines for the management of atrial fibrillation: the task Force for the management of atrial fibrillation of the European Society of Cardiology (ESC). Eur Heart J. 2010;31(19):2369-2429. 
16. January CT, Wann LS, Alpert JS, et al. 2014 AHA/ACC/HRS guideline for the management of patients with atrial fibrillation: a report of the American College of cardiology/American heart association task force on practice guidelines and the heart rhythm society. Circulation. 2014; 130(23):e199-e267.

17. Proietti M, Laroche C, Drozd M, et al. Impact of chronic obstructive pulmonary disease on prognosis in atrial fibrillation: a report from the EURObservational research programme pilot survey on atrial fibrillation (EORP-AF) general registry. Am Heart J. 2016;181:83-91.

18. Goudis CA. Chronic obstructive pulmonary disease and atrial fibrillation: an unknown relationship. J Cardiol. 2017;69(5):699-705.

19. Baum C, Ojeda FM, Wild PS, et al. Subclinical impairment of lung function is related to mild cardiac dysfunction and manifest heart failure in the general population. Int J Cardiol. 2016;218:298-304.

20. Eweda I, Hamada G. Concordance between Doppler and pulsed-wave Doppler tissue imaging in estimation of the degree of left ventricular dysfunction and correlating it to the degree of chronic obstructive pulmonary disease. J Saudi Heart Assoc. 2016;28(1):15-21.

21. Ogi H, Nakano $Y$, Niida $S$, et al. Is structural remodeling of fibrillated atria the consequence of tissue hypoxia? Circ J. 2010;74(9): 1815-1821.

22. Lammers WJ, Kirchhof C, Bonke FI, Allessie MA. Vulnerability of rabbit atrium to reentry by hypoxia. Role of inhomogeneity in conduction and wavelength. Am J Physiol. 1992;262(1):H47-H55.

23. Ogi H, Nakano Y, Niida S, et al. Is structural remodeling of fibrillated atria the consequence of tissue hypoxia? Circ J. 2010;74(9):1815-1821.

24. Xu Y, Sharma D, Du F, Liu Y. The role of Toll-like receptor 2 and hypoxia-induced transcription factor- $1 \alpha$ in the atrial structural remodeling of non-valvular atrial fibrillation. Int J Cardiol. 2013;168(3): 2940-2941.

25. Su F, Zhang W, Chen Y, Ma L, Zhang H, Wang F. Significance of hypoxia-inducible factor- $1 \alpha$ expression with atrial fibrosis in rats induced with isoproterenol. Exp Ther Med. 2014;8(6):1677-1682.

26. Baum C, Ojeda FM, Wild PS, et al. Subclinical impairment of lung function is related to mild cardiac dysfunction and manifest heart failure in the general population. Int J Cardiol. 2016;218:298-304.
27. Agoston-Coldea L, Petrovai D, Mihalcea I, Revnic R, Mocan T, Lupu S Right atrium volume index in patients with secondary pulmonary hypertension due to chronic obstructive pulmonary disease. Acta Cardiol Sin. 2015;31(4):325-336.

28. Kirkham PA, Barnes PJ. Oxidative stress in COPD. Chest. 2013;144(1): 266-273.

29. Harada M, van Wagoner DR, Nattel S. Role of inflammation in atrial fibrillation pathophysiology and management. Circ J. 2015;79(3):495-502.

30. Huang B, Yang Y, Zhu J, et al. Clinical characteristics and prognostic significance of chronic obstructive pulmonary disease in patients with atrial fibrillation: results from a multicenter atrial fibrillation registry study. J Am Med Dir Assoc. 2014;15(8):576-581.

31. Neef PA, Mcdonald CF, Burrell LM, Irving LB, Johnson DF, Steinfort DP. Beta-blockers are under-prescribed in patients with chronic obstructive pulmonary disease and co-morbid cardiac disease. Intern Med J. 2016;46(11):1336-1340.

32. Salpeter SR, Ormiston TM, Salpeter EE, Cochrane Airways Group. Cardioselective beta-blockers for chronic obstructive pulmonary disease. Cochrane Database Syst Rev. 2005;4(8):CD003566.

33. Huang KW, Kuan YC, Chi NF, Huang YH, Luo JC, Chien LN. Chronic obstructive pulmonary disease is associated with increased recurrent peptic ulcer bleeding risk. Eur J Intern Med. 2017;37:75-82.

34. Kang JM, Kim N, Kim JH, et al. Effect of aging on gastric mucosal defense mechanisms: ROS, apoptosis, angiogenesis, and sensory neurons. Am J Physiol Gastrointest Liver Physiol. 2010;299(5):G1147-G1153.

35. Ma L, Chow JY, Cho CH. Effects of cigarette smoking on gastric ulcer formation and healing: possible mechanisms of action. J Clin Gastroenterol. 1998;27(Suppl 1):S80-S86.

36. Luo JC, Lin HY, Lu CL, et al. Dexamethasone inhibits basic fibroblast growth factor-stimulated gastric epithelial cell proliferation. Biochem Pharmacol. 2008;76(7):841-849. 


\section{Supplementary material}

Selection, identification, and calculation

of $\mathrm{CHA}_{2} \mathrm{DS}_{2}$-VASc score, mortality (SIAC-AP, SIAC-CID)

CIAP2 - Classification of Primary Care: cutoff date:

$31 / 12 / 2013$

- Selection of patients with an episode and/or an active conditioning factor with the CIAP2 code K78 - Atrial fibrillation/atrial flutter (SIAC-AP).

- Identification of patients with an episode and/or an active conditioning factor with code K83 - Valvular heart disease (SIAC-AP).

- Calculation of $\mathrm{CHA}_{2} \mathrm{DS}_{2}-\mathrm{VASc}$ score, as defined by the European Society of Cardiology. ${ }^{1}$ This scale awards 1 point for each of the following risk factors: heart failure, arterial hypertension, age 65-74 years, vascular disease (myocardial infarction, peripheral arterial disease, or aortic plates), female gender, and diabetes mellitus, and 2 points for a previous stroke and age $\geq 75$ years.

- History of acute congestive failure with one of the following codes: $\mathrm{K} 74$ - Ischemic heart disease with angina; K75 - Acute myocardial infarction; K76 - Ischemic heart disease without angina; K77 - Heart failure (SIAC-AP) (HF).

- Arterial hypertension: K85 - Elevated blood pressure; K86 - Hypertension uncomplicated; K87 - Hypertension complicated (damage in target organs); K85 - (SIAC-AP).
- $\quad$ Age $\geq 75$ years and gender (SIAC-CID).

- Diabetes mellitus: T89 - Insulin-dependent diabetes mellitus; T90 - non insulin-dependent diabetes mellitus (SIAC-AP).

- Ictus or acute transient ischemia symptoms: K89 Transient cerebral ischemia; K90 - Stroke/cerebrovascular accident; K91 - cerebrovascular disease; K92 - Atherosclerosis/peripheral artery disease; K93 Pulmonary embolism (SIAC-AP).

\section{Anticoagulation/antiaggregation therapy (SIAC-PF):} cutoff date $31 / / 2 / 2013$

Patients with an active prescription of oral anticoagulants and antiaggregants on 31/12/2013 (SIAC-PF).

- The following drugs are identified with an Anatomical, Therapeutic, Chemical classification system code: acetylsalicylic acid and/or clopidogrel, acenocumarol, warfarin (with the calculation of defined daily dose), apixaban, dabigatran, and rivaroxaban.

\section{Reference}

1. Johnson LS, Juhlin T, Engström G, Nilsson PM. Reduced forced expiratory volume is associated with increased incidence of atrial fibrillation: the Malmo preventive project. Europace. 2014;16(2):182-188.
International Journal of COPD

\section{Publish your work in this journal}

The International Journal of COPD is an international, peer-reviewed journal of therapeutics and pharmacology focusing on concise rapid reporting of clinical studies and reviews in COPD. Special focus is given to the pathophysiological processes underlying the disease, intervention programs, patient focused education, and self management protocols.

\section{Dovepress}

This journal is indexed on PubMed Central, MedLine and CAS. The manuscript management system is completely online and includes a very quick and fair peer-review system, which is all easy to use. Visit http://www.dovepress.com/testimonials.php to read real quotes from published authors. 